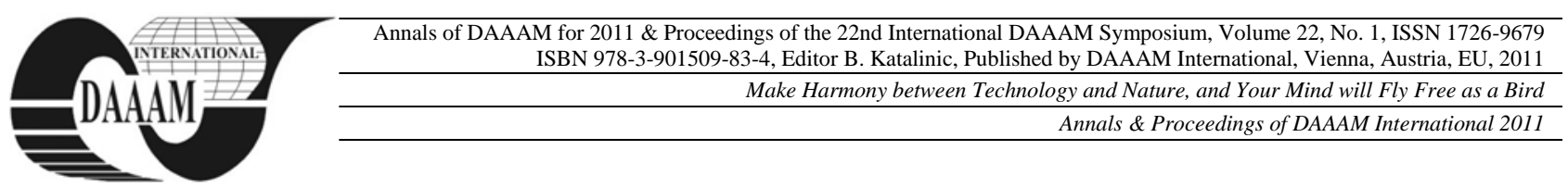

\title{
IMPLEMENTING OF QUALITY MANAGEMENT IN BANKING SECTOR FROM ROMANIA
}

\author{
DRAGOLEA, L[arisa] - L[oredana]; ACHIM, M[oise] I[oan] \& FLESER, M[ihai]
}

\begin{abstract}
The emergence of BRD as a commercial bank occurs in 1990. Taking over the assets and liabilities of the Investment Bank is the basis of its activity, but the general approval for banking activities granted to this entity stimulates the build up of an important network of agencies throughout the country. It is also about ensuring the presence of BRD in the places where the industrial activity is developing in order to pass on its experience in the area of investment loans. Thus, aside from attracting the deposits of companies and individuals, its units are particularly heading towards granting companies loans for investments. The government chose BRD to become the first privatized commercial bank. This choice established the quality of BRD's assets and management. The acquisition of majority stake by Group Société Générale was completed in March 1999; it came at a difficult period marked by resounding insolvencies of banks. This is also the beginning of the massive "bank-alisation" process of individuals.
\end{abstract}

Key words: banking, quality management, QSM, BRD, Romania

\section{INTRODUCTION}

Developed as a universal bank, capable to meet the needs of increasingly larger segments of clients, BRD designed, founded and implemented a Quality Management System (QMS), registered by Moody International as being in accordance with the requirements of the SR EN ISO 9001:2001 standard after conducting a certification audit in December 2002 for the first time. BRD takes advantage of its positive image to the general public and of its quality relationships with enterprises to rapidly develop a portfolio of individual persons. Very quickly, BRD becomes leader on the new products' market, such as banking credits and consumer loans

Adopting QMS at the level of the organization is a strategic decision that "directs and controls the organization in terms of quality", aiming to improve its efficiency and effectiveness in order to increase the satisfaction of stakeholders by meeting their requirements.

\section{THE DESIGN AND IMPLEMENTATION OF QMSIN B.R.D.}

The design and implementation of QMSin B.R.D. takes into account the eight fundamental principles of quality management, defined by SR EN ISO 9001:2001, whose application leads to building an organisational culture based on principles and to improving the bank's performances in order to obtain the leader position of the domestic banking market.

\subsection{Customer focus}

Organizations depend on their clients and therefore should understand their current and future needs, they should meet their requirements and should be concerned with exceeding their expectations. This means understanding the fact that profitability or avoiding losses comes from customer satisfaction, which implies organizing all the processes and directing the entire staff towards the client.

The principle is found in ISO 9001 in the following requirements:

- management commitment;

- customer orientation;

- appointing a new management representative;

- determining the needs and expectations of the client;

- communication with the customer;

- care for customer property.

\subsection{Leadership}

The principle refers to leading people and managing processes; leaders establish the unity of purpose and direction of the organization; they must create and maintain the internal environment in which employees can become fully involved in achieving the objectives of the organization.

The principle is found in ISO 9001 in the following requirements:

- $\quad$ setting goals and policies;

- planning;

- internal communication;

- creating an efficient working environment.

\subsection{Involvement of people}

The staff at all levels represents the essence of an organisation and its total involvement enables their abilities to be used to the benefit of the organization. This principle requires management to encourage employees to contribute and to use their personal experience and knowledge, to be open and work with integrity, to promote valuable ideas regarding continual improvement.

The principle is found in ISO 9001 in the following requirements:

- defining and communicating responsibilities and authorities;

- internal communication;

- identifying the needs for competence;

- participating in the analysis of product requirements

\subsection{Process approach}

A desired result is achieved more efficiently when the activities and related resources are managed as a process. All activities should be seen as processes, because all inputs are transformed into outputs that meet the requirements of the stakeholders, but by adding value, which determine processes to be dynamic.

\subsection{System approach to management}

Identifying, understanding and managing interrelated processes as a system contributes to organization's efficiency 
and effectiveness in achieving its objectives. System approach to management means managing the organisation as a system of processes, so that all processes will fit, inputs and outputs will be interrelated so that there will be no omissions that delay the unreeling of the following process, resources will fuel processes, performance will be monitored and the received information will lead to changes in activities and all involved parties will work together to achieve the organisation's goals. A system is not a mere collection of elements, procedures and tasks, but a set of interrelated processes.

The principle is found in ISO 9001 in the following requirements:

- establishing, implementing and maintaining a quality management system;

- the processes' intertwining, interrelating and succession;

- motoring, measuring and analysing processes.

\subsection{Continual improvement}

Of the global performance should be the permanent objective of the organisation. This option actually represents an "insurance policy" regarding the organisation's perennial feature in its fight with competitors. As a result, each member of the organisation has the task to monitor continuously the three key areas where improvement is necessary, so that organisations achieve and maintain success.

These three areas are:

- its own performance, seeking ways to improve (through training and self-education);

- its own methods, seeking better ways to conduct activity (innovators);

- its own tasks, seeking new tasks that will increase the organisation's capacity (inventors)

The principle is found in ISO 9001 in the following requirements:

- improving processes;

- management commitment;

- identifying improvements and implementing corrective actions:

- reviewing documents and processes to find opportunities for improvement through preventive actions.

\subsection{Factual approach to decision making}

Effective decisions are based on the analysis of data and information. Facts and evidences obtained from observations supplied by qualified personnel lead to decision-making. As a result, measurement systems (statistical techniques) and methods of interpretation of facts are required, this approach leading to control of evidence and not to decisions made on the basis of opinions or emotions.

The principle is found in ISO 9001 in the following requirements:

- records that document evidences;

- approvals, decisions based on evidences;

- analysis conducted by management;

- control of measuring and monitoring devices;

- analysing data to gather evidence.

\subsection{Mutually beneficial supplier relationships}

An organisation and its suppliers are interdependent, and a mutually beneficial relationship enhances the ability of both to create value, which implicitly leads to increased profits.

The principle is found in ISO 9001 in the following requirements:

- control of suppliers;

- assessing suppliers;

- analysing and reviewing data about suppliers
Adopting the ISO 9000 standards doesn't mean automatic improvement of the business performance, but the standards may serve as a guide in choosing how "to do things right the first time", and their implementation within an organisation depends on the leadership that sets the meaning, direction and creates the adequate internal environment to achieve objectives.



Fig. 1. Fundamental principles of quality management

The structure of the standard complies with the PDCA methodology (Plan-Do-Check-Act), the model of the American statistician Dr. W. Edwards Deming being the way in which the processes' management is conducted within the quality system implemented in BRD.

\section{CONCLUSION}

The current economic situation and the positions taken by banks present on the Romanian market make the implementation of quality management within the banking system more important than ever. At this time, the banking market's trend shows a slight increase, new business opportunities that must be capitalized emerge at local and national level, but, at the same time, there is also a significant increase of the customers' demands in their relationship with banks. The banks that will be able to adequately combine its sales offer with the quality of service have real chances to increase their market share (what all banks are striving for) and, implicitly, their profit.

\section{REFERENCES}

Dragulanescu, N., (2005). Managementul in servicii, Editura Economica, Bucuresti, 2005

Ungureanu, S. (2004). Introducere in managementul calitatii, Editura Romprint, Brasov, 2004

Popescu, M., Paleriu, E. (2002). Managementul calitatii, Editura Infomarket

Ileana, I., Muntean, M., Kadar, M., Rotar, C., Risteiu, M., Decision support system built in fuzzy logic, Proceedings of the 6-th International Conference on Theory and Applications in Mathematics and Informatics - ICTAMI 2009, ISBN 1582-5389, Alba Iulia, Romania, September, 3-6, 2009

*** Norme, instructiuni si regulamente interne ale BRD Romania, www.brd.ro

*** SR EN ISO 9000:2001

*** SR EN ISO 9000:2000

$* * *$ SR EN ISO 9001:2000 